\title{
ASSESSING AND \\ UNDERSTANDING THE IMPACT OF STRATOSPHERIC DYNAMICS AND VARIABILITY ON THE EARTH SYSTEM
}

by Edwin P. Gerber, Amy Butler, Natalia Calvo, Andrew Charlton-Perez, Marco Giorgetta, Elisa Manzini, Judith Perlwitz, Lorenzo M. Polvani, Fabrizio Sassi, Adam A. Scaife, Tiffany A. Shaw, Seok-Woo Son, and Shingo Watanabe

New modeling efforts will provide unprecedented opportunities to harness our knowledge of the stratosphere to improve weather and climate prediction.

0 bservational and modeling studies over the past two decades have fundamentally changed our understanding of the stratosphere's role in surface weather and climate. Interactions between the stratosphere and other components of the Earth system, from the troposphere to the deep ocean, possibly even the ice sheets of Greenland and Antarctica, reveal coupling across a wide range of spatial and temporal scales. In response to these advances, operational forecast, seasonal prediction, and coupled climate models are "raising their lids," adding model layers, incorporating more stratospheric processes, and assimilating data higher into the stratosphere than ever before.
AfFILIATIONS: Gerber-Center for Atmosphere Ocean Science, Courant Institute of Mathematical Sciences, New York University, New York, New York; BUtLeR-NOAA/NWS/NCEP/ Climate Prediction Center, Camp Springs, Maryland; CalvoDepartment de Física de la Tierra II, Universidad Complutense de Madrid, Madrid, Spain, and Atmospheric Chemistry Division, NCAR, Boulder, Colorado; CharLton-Perez-Department of Meteorology, University of Reading, Reading, United Kingdom; GIORGETTA and MANZINI-Max-Planck-Institut für Meteorologie, Hamburg, Germany; PERLWITZ-Cooperative Institute for Research in Environmental Sciences, University of Colorado, and NOAA/ Earth System Research Laboratory/Physical Sciences Division, Boulder, Colorado; PolvanI-Department of Applied Physics and Applied Mathematics, and Department of Earth and Environmental Sciences, Columbia University, New York, New York; SAssISpace Science Division, Naval Research Laboratory, Washington, D.C.; SCAIFE-Met Office Hadley Centre, Exeter, United Kingdom;
SHAW - Lamont-Doherty Earth Observatory, and Department of Applied Physics and Applied Mathematics, Columbia University, New York, New York; SoN-Department of Atmospheric and Oceanic Sciences, McGill University, Montreal, Quebec, Canada; WATANABE-Research Institute for Global Change, Japan Agency for Marine-Earth Science and Technology, Yokohama, Japan CORRESPONDING AUTHOR: Edwin Gerber, Courant Institute of Mathematical Sciences, New York University, 25I Mercer Street, New York, NY 10012

E-mail: gerber@cims.nyu.edu

The abstract for this article can be found in this issue, following the table of contents.

DOI:10.1175/BAMS-D-II-00145.I

In final form I November 2011

(O)2012 American Meteorological Society 
TABLE I. Anticipated simulations from CMIP5 models with enhanced stratospheric representation (contact information for each modeling center is available at www.sparcdynvar.org/storage/CMIP5_hitop_models.pdf). RCP = Representative Concentration Pathway.

\begin{tabular}{|c|c|c|c|c|}
\hline Institute/group & Full name of model & Atmospheric resolution & Model top & RCP scenarios \\
\hline NSF-DOE- NCAR & CESMI(WACCM) & $144 \times 96 \times L 66$ & $6 \cdot 10^{-6} \mathrm{hPa}$ & $2.6,4.5,8.5$ \\
\hline \multirow{2}{*}{ CMCC } & CMCC-CMS & $\mathrm{T} 63 \times \mathrm{L} 95$ & $0.01 \mathrm{hPa}$ & 4.5 \\
\hline & CMCC-CESM & T31 $\times$ L39 & $0.01 \mathrm{hPa}$ & 8.5 \\
\hline \multirow{2}{*}{$\begin{array}{l}\text { EC-Earth } \\
\text { consortium }\end{array}$} & \multirow{2}{*}{ EC-Earth } & TI59 × L9I & $0.01 \mathrm{hPa}$ & 4.5 \\
\hline & & $\mathrm{TI} 59 \times \mathrm{L} 6 \mathrm{I}$ & $5 \mathrm{hPa}$ & $4.5,8.5$ \\
\hline NASA GSFC & GEOS-5 & $1^{0} \times 1.25^{0} \times L 72$ & $0.01 \mathrm{hPa}$ & Decadal prediction runs \\
\hline NOAA GFDL & GFDL CM3 & $\sim 200 \mathrm{~km} \times \mathrm{L} 48$ & $0.017 \mathrm{hPa}$ & All RCPs \\
\hline NASA GISS & GISS-E2 & $90 \times 144 \times \mathrm{L} 40$ & $0.1 \mathrm{hPa}$ & All RCPs \\
\hline $\mathrm{MOHC}$ & HadGEM2-CC & $192 \times 145 \times \mathrm{L} 60$ & $84 \mathrm{~km}$ & $4.5,8.5$ \\
\hline \multirow{2}{*}{ IPSL } & \multirow{2}{*}{ IPSL-CM5 } & $96 \times 95 \times$ L39 & \multirow{2}{*}{$65 \mathrm{~km}$} & \multirow{2}{*}{4.5} \\
\hline & & $144 \times 143 \times 139$ & & \\
\hline \multirow{2}{*}{ MIROC } & MIROC-ESM & \multirow{2}{*}{$\mathrm{T} 42 \times \mathrm{L} 80$} & \multirow{2}{*}{$85 \mathrm{~km}$} & \multirow{2}{*}{ All RCPs } \\
\hline & MIROC-ESM-CHEM & & & \\
\hline \multirow{2}{*}{ MPI-M } & MPI-ESM-LR & $\mathrm{T} 63 \times \mathrm{L} 47$ & $0.01 \mathrm{hPa}$ & $2.6,4.5,8.5$ \\
\hline & MPI-ESM-MR & $\mathrm{T} 63 \times \mathrm{L} 95$ & $0.01 \mathrm{hPa}$ & $2.6,4.5,8.5$ \\
\hline MRI & MRI-ESMI & TLI59 $\times$ L48 & $0.01 \mathrm{hPa}$ & $4.5,8.5$ \\
\hline
\end{tabular}

CESMI(WACCM): Community Earth System Model version I (Whole Atmosphere Community Climate Model)

CMCC: Centro Euro-Mediterraneo per i Cambiamenti Climatici

CMCC-CESM: Centro Euro-Mediterraneo per i Cambiamenti Climatici Carbon Earth System Model

CMCC-CMS: Centro Euro-Mediterraneo per i Cambiamenti Climatici Coupled Modeling System

GEOS-5: Goddard Earth Observing System Model version 5

GFDL CM3: Geophysical Fluid Dynamics Laboratory Coupled Model version 3.0

GISS-E2: Goddard Institute for Space Studies Model E2

HadGEM2-CC: Hadley Centre Global Environmental Model version 2-Carbon Cycle configuration

IPSL: L’Institut Pierre-Simon Laplace

IPSL-CM5: L'Institut Pierre-Simon Laplace Coupled Model version 5

MIROC: Japan Agency for Marine-Earth Science and Technology, Atmosphere and Ocean Research Institute (The University of

Tokyo), and National Institute for Environmental Studies

MIROC-ESM: Model for Interdisciplinary Research on Climate Earth System Model

MIROC-ESM-CHEM: Model for Interdisciplinary Research on Climate Earth System Model, atmospheric chemistry coupled version MOHC: Met Office Hadley Centre

MPI-ESM-LR: Max Planck Institute Earth System Model, low resolution

MPI-ESM-MR: Max Planck Institute Earth System Model, medium resolution

MPI-M: Max Planck Institute for Meteorology

MRI: Meteorological Research Institute

MRI-ESMI: Meteorological Research Institute Earth System Model version I

NASA GISS: National Aeronautics and Space Administration Goddard Institute for Space Studies

NASA GSFC: National Aeronautics and Space Administration Goddard Space Flight Center

NOAA GFDL: National Oceanic and Atmospheric Administration Geophysical Fluid Dynamics Laboratory

NSF-DOE-NCAR: National Science Foundation-Department of Energy-National Center for Atmospheric Research 
The Modelling the Dynamics and Variability of the Stratosphere-Troposphere System (DynVar) activity of the World Climate Research Programme's (WCRP) Stratospheric Processes and their Role in Climate (SPARC) project is a multidisciplinary research forum focused on the impact of stratospheric dynamics and variability. In this article, we review recent results connecting the stratosphere to surface weather and climate, and explore key open questions facing the research community. Following a recent workshop (Manzini et al. 2011), DynVar is coordinating a new effort to address these questions with the aid of two emerging multimodel datasets. The first is part of the Coupled Model Intercomparison Project phase 5 (CMIP5) where, for the first time, several climate prediction centers will seek to accurately represent the stratosphere in coupled model integrations. A list of participating models is shown in Table 1 . The second, the Stratosphere Resolving Historical Forecast Project (Strat-HFP), is a multimodel set of seasonal hindcasts, organized to elucidate the role of the stratosphere on intraseasonal time scales. The Strat-HFP is a subproject of WCRP's Climate Variability and Predictability (CLIVAR) effort to improve seasonal to interannual prediction, and further information is available on their website (www.wcrp-climate.org /wgsip/chfp/stratHFP.shtml). These new datasets will offer unrivaled opportunities to explore the role of the stratosphere in the Earth system, and they may allow us to improve our ability to forecast future weather and climate, on time scales from just a few days to centuries.

\section{THE STRATOSPHERIC ROLE IN WEATHER} AND CLIMATE. Exploration of the stratosphere began in the second half of the nineteenth century, when technological advances first freed scientists or, perhaps more importantly, their instruments from the ground. The lapse rate of the free troposphere, approximately $7 \mathrm{~K} \mathrm{~km}^{-1}$, had been established from mountain-based measurements in the eighteenth century; Hermann von Helmholtz (among others) speculated that if this lapse rate continued to higher altitudes, then the atmosphere would reach absolute zero near $30 \mathrm{~km}$. Daring hot air balloon ascents revealed a reduction of the lapse rate above $12 \mathrm{~km}$, a hint of what we now know to be the tropopause, but the risky ascents also cost the lives of aspiring high-altitude meteorologists. ${ }^{1}$ It required unmanned balloon measurements, precursors of the modern radiosonde, by Teisserenc de Bort (1902) and Assmann (1902) to safely and systematically illuminate the structure of the upper atmosphere. They revealed a stably stratified expanse of air where temperature actually increases with height, as illustrated with modern data in Fig. 1, above the unsettled motion below, inspiring Teisserenc de Bort to separate the turbulent troposphere ("the sphere of change," from the Greek

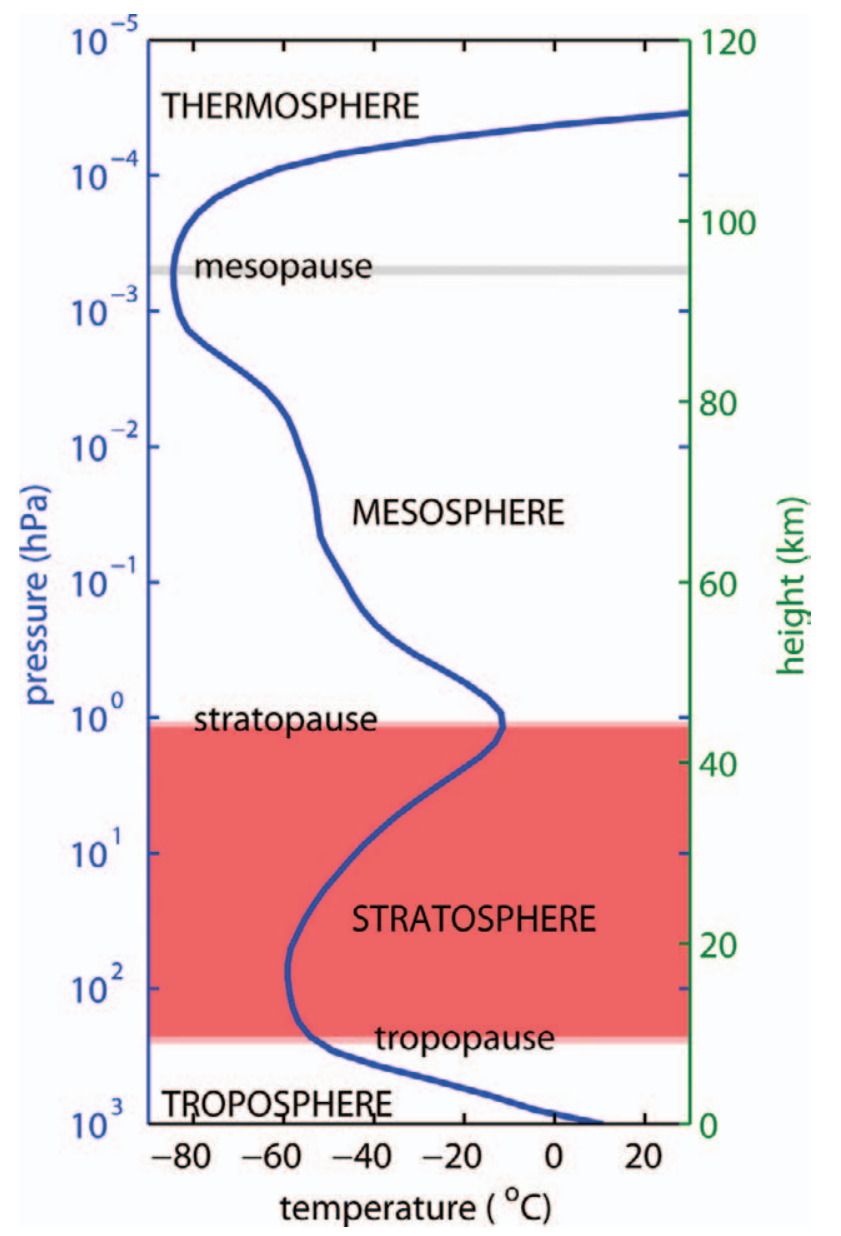

FIG. I. Sample vertical temperature profile of the atmosphere, based on the Jan zonal-mean temperature at $40^{\circ} \mathrm{N}$ from the Committee on Space Research (COSPAR) International Reference Atmosphere 1986 model (CIRA-86). At the time of its discovery, observations were reliable only up to $15 \mathrm{~km}$, and the "stratosphere" was taken to include everything above the tropopause. The modern stratosphere is bounded by the stratopause, above which temperatures begin to decline with height. Recall that the mass of the atmosphere is proportional to pressure; the stratosphere contains about $10 \%-20 \%$ of the total mass of the atmosphere, and everything above the stratopause, just $0.1 \%$.

\footnotetext{
${ }^{1}$ Please see Hoinka (1997) and Labitzke and Van Loon (1999) for a more detailed account of the early history of upper-atmosphere exploration.
} 
tropos, to turn or whirl) from the laminar stratosphere above (literally "the sphere of layers," from the Latin stratus, "spread out").

Pioneering work by Scherhag (1952), however, showed that this seemingly stable part of the atmosphere is also susceptible to violent change, with wind and temperature swings that rival those experienced in the most powerful fronts at the surface. Concurrently, Brewer (1949) and Dobson (1956) revealed that the stratosphere actively circulates from the equator to the poles, a meridional overturning now known as the Brewer-Dobson circulation. Key advances in stratospheric dynamics in the 1960s and 1970s linked stratospheric variability to tropospheric phenomena. Direct interactions are primarily at the extremes of the spatial spectrum, involving planetary-scale waves and small-scale gravity waves, but notably not synoptic waves (e.g. Charney and Drazin 1961). However, conventional wisdom maintained that interactions were primarily one way-the stratosphere passively responding to forcing from the more massive troposphere below. It required advances in observational analysis and modeling capability in the 1980s and 1990s to establish genuinely two-way interactions between the stratosphere and world below, setting the stage for the recent explosion of research on the role of the stratosphere in the Earth system.
Short-range weather prediction. An early numerical study by Boville and Baumhefner (1990) explored the impact of the stratosphere on tropospheric predictability, finding that tropospheric error growth rates increased when the stratosphere of their model was degraded. The errors, however, were relatively small until about 20 days, and thus easily overwhelmed by uncertainty in the initial conditions. Subsequent improvements in numerical weather prediction (NWP) skill have now made it possible to identify the impact of stratospheric perturbations on shorter time scales. Charlton et al. (2004) show that tropospheric forecast skill declines significantly when the initial conditions in the stratosphere are intentionally misspecified, highlighting the importance of the stratospheric state for tropospheric forecasts. In a complementary study, Jung and Barkmeijer (2006) find that forcing perturbations applied only in the stratosphere can impact the troposphere in just a few days, demonstrating the potential for model error in the stratosphere to corrupt a surface forecast.

A number of NWP centers now include a better representation of the stratosphere to improve short-range forecasts, as illustrated in Fig. 2. The improvement stems in part from the ability to assimilate data from satellite channels that project into the troposphere but extend significantly into the stratosphere. These broad channels cannot be effectively incorporated without a representation of the physics of the middle atmosphere. Clarifying the extent to which a well-resolved stratosphere improves tropospheric forecasts, over and above this initial condition effect, is an active field of research.

The difficulty of raising the model top in NWP systems stems in part from computational constraints associated with the stratospheric circulation; not only must one represent additional model layers but high stratospheric wind velocities (which can exceed $180 \mathrm{~m}$ $\mathrm{s}^{-1}$, or $350 \mathrm{kt}$ ) may require a reduced time step. To address these limitations, more sophisticated numerical treatment of the stratosphere, such as upper-boundary nesting (McTaggart-Cowan et al. 2011), is being developed to allow models to more efficiently represent stratospheric conditions but still capture the predictive skill. 
Intraseasonal predictability. The impact of the stratosphere on tropospheric forecast skill increases on intermediate time scales, from about a week to a season, as highlighted by a 2010 National Academy of Science study focused on improving seasonal forecasts (National Research Council 2010). The potential for extended predictability stems in part from the slow radiative relaxation rates of the lower stratosphere (Newman and Rosenfield 1997); perturbations in this region are slow to recover, and so they can provide extended memory to the atmospheric circulation on monthly time scales (Baldwin et al. 2003). The potential for predictability, however, can only be realized during seasons when the stratosphere is actively coupled with the troposphere below: winter in the Northern Hemisphere and late spring in the Southern Hemisphere.

Radiative cooling during the polar night leads to a powerful westerly jet in the stratosphere. This "polar vortex," however, can be destroyed by bursts of planetary wave activity from the troposphere in just a matter of days (Matsuno 1971). Associated with the weakening of the winds is a dramatic warming of the polar stratosphere, locally up to $80 \mathrm{~K}$, so that these events are known as stratospheric sudden warmings (SSWs) (e.g., Scherhag 1952; Labitzke 1972). SSWs occur about every other year in the Northern Hemisphere, but they have been observed only once in the Southern Hemisphere (in September 2002), where planetary wave forcing is weaker. In the Southern Hemisphere, the variability of the polar vortex is highest in November, when winter westerlies transition to summer easterlies.

Baldwin and Dunkerton (2001) demonstrate that these stratospheric anomalies propagate downward into the troposphere in approximately one week, and that they can impact the tropospheric circulation for up to two months. The downward signal from the stratosphere to the troposphere is well characterized by the "annular mode," the dominant mode of intraseasonal variability in the extratropical atmosphere (Thompson and Wallace 1998). In the upper atmosphere, the annular mode tracks the intensity of the polar vortex, where a positive index implies a strong vortex, while in the troposphere it characterizes the meridional position of the midlatitude jet, where a positive index implies a poleward shift of the jet. Composites formed with the annular mode index, computed separately at each height, show the downward impact of SSWs in Fig. 3. We show the response in both reanalyses and models of varying complexity to highlight the robustness of the phenomenon (see the sidebar for more information).

The negative index of the tropospheric annular mode (i.e., an equatorward shift of the midlatitude jet) following an SSW implies colder weather and more snow in the northeastern United States and northern Europe (Thompson and Wallace 2001). Christiansen 
(2005) isolates this stratospheric impact on surface weather with a statistical forecast model, Kuroda (2008) and Mukougawa et al. (2009) in NWP models, and Kolstad et al. (2010) in reanalyses and coupled climate models. Similar perturbations to tropospheric weather, but of opposite sign, are observed when the stratospheric vortex is abnormally strong, so-called polar intensification events (Limpasuvan et al. 2005). While stratospheric events offer the opportunity for extended predictability once they occur, they can be difficult to forecast far in advance, as they are initiated by tropospheric planetary waves (e.g., Polvani and Waugh 2004; Gerber et al. 2009). Cohen et al. (2007), however, suggest that early snowfall over Eurasia can amplify the planetary wave pattern in the troposphere, increasing the likelihood of a disturbed vortex in midwinter. The final, springtime warming of the polar vortex also offers the potential for improved tropospheric forecasts (Black et al. 2006). Focusing on the Southern Hemisphere, Roff et al. (2011) demonstrate that extended forecasts during austral spring can be enhanced by increasing the resolution of the stratosphere.

In addition to the zonal coupling between the polar vortex and jet stream, Perlwitz and Harnik

\section{MODELING THE MIDDLE ATMOSPHERE: CHEMISTRY-CLIMATE MODELS}

M iddle atmospheric modeling with general circulation models (GCMs) has a long history (e.g., Fels et al. 1980; Boville 1984). To date, the most sophisticated representation of the stratosphere-troposphere system is found in Chemistry-Climate models (CCMs). A CCM is an atmospheric model designed to predict changes in stratospheric ozone. It is run at comparable horizontal resolution to the atmospheric component of a coupled climate model, but with finer vertical resolution in the middle atmosphere and a model lid generally above the stratopause. Most importantly, CCMs simulate the processes involved in stratospheric ozone chemistry, including the heterogeneous reactions on polar stratospheric clouds responsible for the Antarctic ozone hole. Thus, scenario forcings must include relevant ozone-depleting substances, in addition to greenhouse gases. Given the computation resources needed to simulate stratospheric chemistry, in addition to more sophisticated gravity wave and radiative transfer parameterizations appropriate for the middle atmosphere, to date most CCMs have been run with prescribed sea surface temperatures, often taken from reanalyses or coupled climate integrations. The first international modeling intercomparison of the tropospheremiddle atmosphere system was reported by Pawson et al. (2000). For more information on the latest generation of CCMs, see Eyring et al. (2010), summarizing the second CCM Validation Activity (CCMVal2) of SPARC.
(2003) show evidence of direct coupling between planetary waves in the stratosphere and the troposphere. While a weaker polar vortex is associated with the breaking of planetary waves, a stronger vortex is associated with the reflection of planetary waves, leading to correlation between tropospheric and stratospheric planetary wave structures on weekly time scales. There is evidence that climate change, particularly ozone loss in the Southern Hemisphere, has modulated this intraseasonal coupling in recent decades (Shaw et al. 2011).

Interannual predictability. The natural variability of the Earth system on interannual time scales is dominated by coupled atmosphere-ocean modes-in particular, El Niño-Southern Oscillation (ENSO). The stratosphere appears to play an important role in transmitting the tropical ENSO signal to the midlatitudes (e.g., Bell et al. 2009). Extratropical upward wave propagation intensifies during warm ENSO events in boreal winter, modulating the meridional overturning circulation of the stratosphere and the stratospheric polar vortex (Garcia-Herrera et al. 2006). The vortex anomalies then propagate downward, affecting the midlatitudes in the troposphere (Cagnazzo and Manzini 2009; Ineson and Scaife 2009). The weakened polar vortex during El Niño winters tends to cause colder, snowier winters in Europe. Brönnimann et al. (2004), for instance, relate the extreme cold winters of 1940-42 to the stratospheric variability driven by El Niño. More recent work has explored the potential for coupling between the stratosphere and ocean apart from ENSO, connecting decadal variations in the Atlantic with the variability of the boreal stratospheric vortex (Schimanke et al. 2011).

The stratospheric circulation itself explicitly carries memory on interannual time scales in the quasi-biennial oscillation (QBO), an oscillation of easterly and westerly jets in the tropical stratosphere with a period of approximately 28 months. There is evidence of QBO influence at the surface (e.g., Coughlin and Tung 2001; Thompson et al. 2002; Crooks and Gray 2005), and recent studies show evidence for increased interannual predictability from the QBO (Boer and Hamilton 2008; Marshall and Scaife 2009). The mechanism may involve the stratospheric polar vortex, as QBO winds modulate the upward propagation of waves in the extratropics (Holton and Tan 1980; Calvo et al. 2009).

The stratosphere also plays an important role in determining the climate response to volcanic and solar forcing. Scattering of incoming solar radiation by stratospheric aerosols after volcanic eruptions leads 
to surface cooling, up to $0.1-0.2 \mathrm{~K}$ in the global mean (Robock and Mao 1995). While tropospheric aerosols are washed out of the atmosphere relatively quickly by the hydrological cycle, stratospheric aerosols last up to two years, giving persistence to the volcanic signal. The Brewer-Dobson circulation plays a role in the global response, lifting aerosols upward in the tropics and spreading them across the extratropics of both hemispheres. For this reason, tropical volcanic eruptions have much more global, long-lasting impacts on climate than comparable eruptions in the high latitudes. While sulfate aerosols cool the surface by scattering incoming radiation, they warm the stratosphere by absorbing in the infrared (Angell 1997). This stratospheric temperature signal could lead to potentially unexpected changes in surface temperature on regional scales; Europe appears to experience warmer winters following major volcanic eruptions because warming in the tropical lower stratosphere may lead to a stronger, colder polar vortex, shifting the tropospheric jet stream poleward (Robock and Mao 1992). Confirmation of this effect in models, however, has proved difficult (e.g., Marshall et al. 2009).

The net radiative perturbation associated with the $11-y r$ solar cycle is relatively small, approximately $0.2 \mathrm{~W} \mathrm{~m}^{-2}$ averaged over the Earth's surface, less than $0.1 \%$ of the total incoming solar radiation. The relative variance is considerably larger in the UV range of the spectrum, and thus leads to more substantial perturbations in stratospheric ozone and temperature (e.g., Haigh 1996; Gray et al. 2010). Changes in stratospheric temperature gradients could affect the wave coupling between the troposphere and stratosphere, potentially impacting regional surface climate (e.g., Kodera and Kuroda 2002). Thus, the primary impact of solar variability on the troposphere may be on the regional scale, related to solar-induced changes in the Brewer-Dobson circulation and the lowermost tropical stratosphere (Matthes et al. 2006). Untangling the 11-yr solar cycle signal from that of ENSO or the $\mathrm{QBO}$, however, is not a trivial task, both in the tropics (e.g., Marsh and Garcia 2007) and the extratropics (e.g., Camp and Tung 2007). More recent analysis of perturbations associated with the solar cycle by Lean and Rind (2008) and new satellite-based measurements of the current cycle by Haigh et al. (2010) have in fact questioned our current understanding of solar impacts.

Anthropogenic climate change. On decadal time scales and longer, the impact of anthropogenic forcing on the stratosphere becomes significant. The most notable example is the destruction of stratospheric ozone by chlorofluorocarbons and other halogenated compounds. The Antarctic ozone hole, a near-complete destruction of ozone between 12 and $25 \mathrm{~km}$, forms each austral spring when sunlight first breaks on activated halogen reservoirs built up over the polar night (Farman et al. 1985; Solomon 1999). The depletion of ozone cools the lower stratosphere by up to $\sim 10 \mathrm{~K}$, strengthening the westerly winds in the polar vortex and delaying the seasonal transition from winter westerlies to summer easterlies (Thompson and Solomon 2002).

This perturbation to the lower stratosphere is, in turn, associated with a poleward shift of the tropospheric jet stream and storm track from December to February. Chemistry-Climate Models (CCMs) run with and without ozone-depleting substances have directly attributed the observed stratospheric cooling, and thus the corresponding changes in the tropospheric circulation, to stratospheric ozone loss (e.g., Perlwitz et al. 2008). Greenhouse gas (GHG)induced warming of the troposphere also forces a poleward shift of the tropospheric jet stream (e.g., Kushner et al. 2001; Yin 2005), so that over the past four decades, both ozone loss and GHG increases have been driving the poleward shift of the Southern Hemisphere storm track. This raises two questions: first, over the observed record, how much of Southern Hemisphere climate change should be attributed to ozone loss versus GHG increases? and second, what should be anticipated in the future, when the effects of the expected ozone hole recovery oppose those due to GHG increases?

These questions are partially answered by an unintentional experiment conducted by coupled climate model simulations prepared for the Intergovernmental Panel on Climate Change's Fourth Assessment Report (IPCC AR4). As explored by Son et al. (2008), stratospheric ozone was not mandated in the CMIP3, leaving each modeling group to choose a strategy. Roughly half of the models included ozone loss and recovery in their integrations, while the other half kept climatological ozone fixed. As shown in Fig. 4, models with steady ozone exhibit a poleward shift of the jet in both the twentieth and twenty-first centuries, while models with time-varying ozone exhibit stronger jet stream trends in the twentieth century, when ozone and GHG changes work together, but exhibit almost no trend at all in the twenty-first century, as the two forcings oppose one another, effectively canceling each other out. Multimodel analyses (e.g., Son et al. 2008; Fogt et al. 2009) and attribution studies with individual models (Arblaster 
and Meehl 2006; Perlwitz et al. 2008; Polvani et al. 2011; McLandress et al. 2011) all suggest that ozoneinduced cooling of the polar stratosphere has dominated Southern Hemisphere climate change in austral spring and summer over the last few decades. It is also clear that ozone forcing will play an important role in future climate change, and it is supposed to be included in all coupled climate models in the CMIP5 experiments.

The shift in the austral jet stream has had substantial implications on the hydrological cycle of the Southern Hemisphere, deep into the subtropics (Kang et al. 2011). Its effect on global climate may be magnified through coupling with the Southern (a) ERA40: 1960-1999

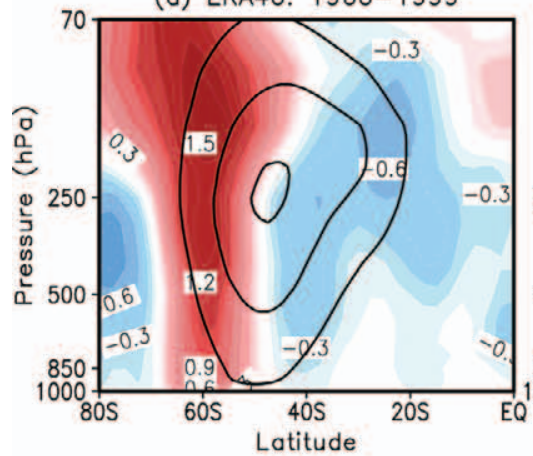

(b) CMIP3 Fixed O3: 1960-1999

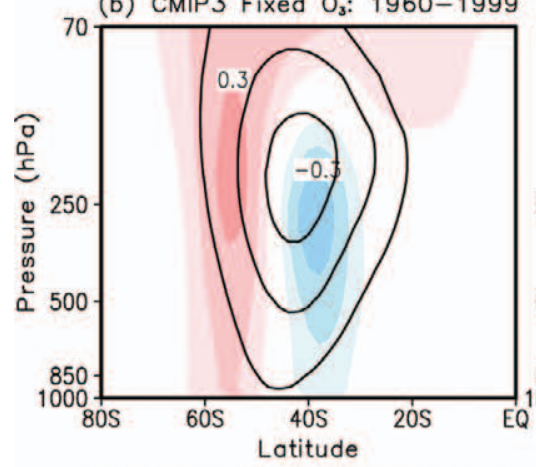

(c) CMIP3 $\mathrm{O}_{3}$ Decr.: 1960-1999

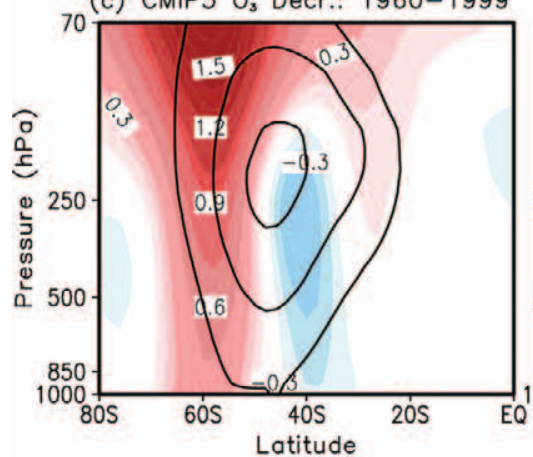

(d) CCMVal2 Os Decr.: 1960-1999

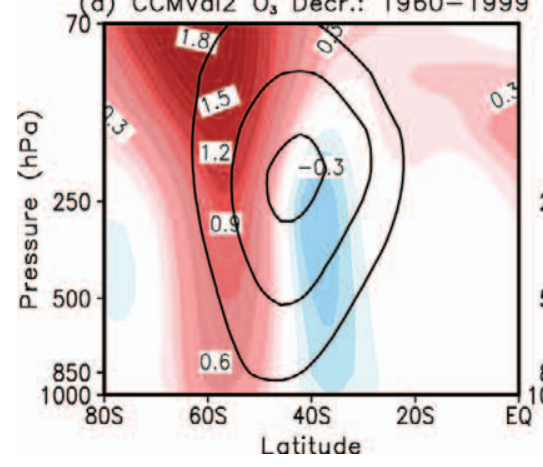

(e) ERA40: 1979-1999

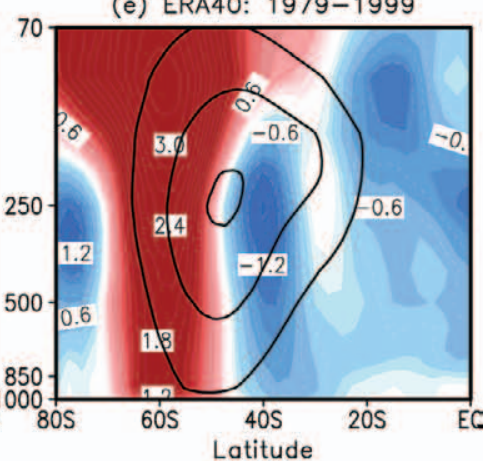

(f) CMIP3 Fixed $\mathrm{O}_{3}: 2000-2079$

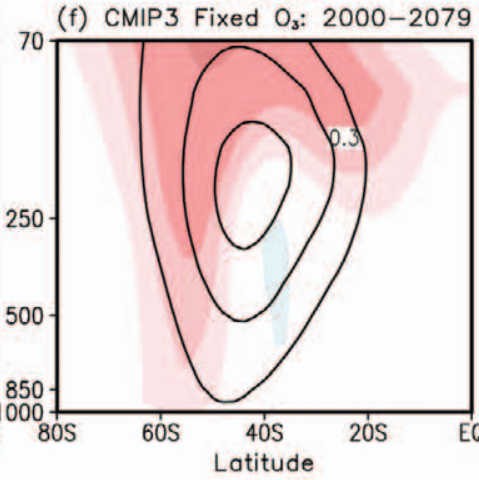

(g) CMIP3 $\mathrm{O}_{3}$ Incr:: 2000-2079

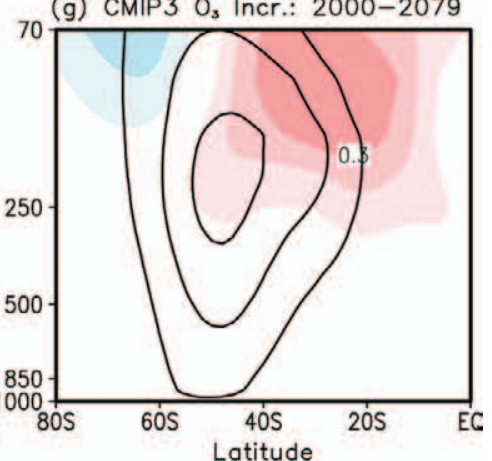

(h) CCMVal2 Os Incr.: 2000-2079

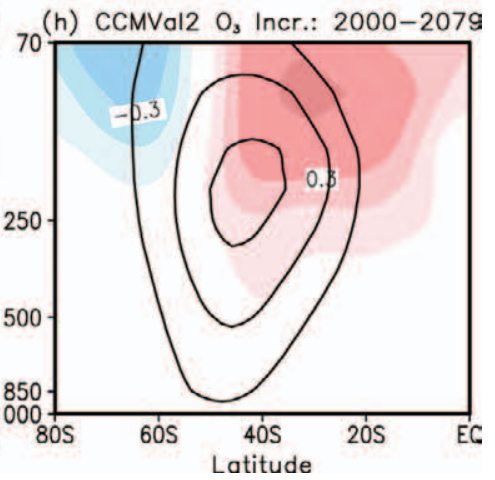

Ocean, the primary sink of atmospheric $\mathrm{CO}_{2}$ in the oceanic carbon cycle. Studies have suggested that the increased ventilation of carbon-rich deep water driven by the poleward shift of the austral jet stream has

FIG. 4. Impact of stratospheric ozone loss and recovery on recent and projected climate change in the Southern Hemisphere. Shading shows trends in December-February (DJF) zonalmean zonal wind ( $\mathrm{m} \mathrm{s}^{-1}$ decade $\left.{ }^{-1}\right)$ during (a)-(d) 1960-99, the period of ozone loss; and (f)-(h) 2000-79, the period of expected ozone recovery. Black contours denote the climatological jet from 1960 to 1999. (a) Trends based on ERA-40: the positive (negative) trends on the poleward (equatorward) flanks of the mean jet characterize a poleward shift of the jet. As reanalyses in the Southern Hemisphere are less reliable in the presatellite era, we also show trends (e) from 1979 to 1999 to confirm their structure. Trends are stronger over this shorter period, which captures the peak changes in ozone depletion, but we focus on the full period, 1960-99, in the models as the larger sampling reduces statistical uncertainty. (b),(f) Results for CMIP3 models forced with fixed ozone; here, the trend is underestimated over the past four decades, but it continues with comparable strength in the future. (c),(g) Results from CMIP3 models that were forced with time-varying ozone; these models better capture observed trends and suggest that stratospheric ozone and tropospheric GHG forcings will effectively cancel out over the next 80 years. (d),(h) Based on the second CCM Validation Activity models (CCMVal2) with interactive ozone chemistry. Similarities between the four bottom panels suggest that CMIP3 models forced with specified ozone appear to capture the essential impact of stratospheric ozone trends. 
both weakened the Southern Ocean carbon sink (e.g., Lovenduski et al. 2008) and accelerated ocean acidification (Lenton et al. 2009). A note of caution may be in order, as the relatively coarse resolution of the ocean simulated in coupled models may be missing feedbacks within the oceanic circulation that would make it less sensitive to atmospheric forcing (e.g., Böning et al. 2008). Changes in the coupled atmosphere-ocean circulation may also affect sea ice trends in the Southern Ocean (Turner et al. 2009), but a lack of agreement between models suggests the need for further study (Sigmond and Fyfe 2010).

There is not a comparable ozone hole in the Northern Hemisphere because the boreal winter vortex is warmer, which limits the formation of polar stratospheric clouds crucial to the chemistry of rapid ozone loss. Model simulations of twentiethcentury and twenty-first-century circulation trends in the Northern Hemisphere, however, indicate an important role of the stratosphere in the coupled stratosphere-troposphere response to anthropogenic forcing. Most models are unable to capture the observed poleward trend of the Northern Hemisphere tropospheric storm track from the 1970s to the mid1990s. Prescribing trends in the lower stratosphere makes it possible to capture the tropospheric trends without affecting the global-mean warming signal (Scaife et al. 2005), and improved stratospheric variability in coupled climate models has been shown to improve the simulation of twentieth-century climate (Dall'Amico et al. 2010). Sigmond et al. (2008) find that the response of the tropospheric storm track to a doubling of $\mathrm{CO}_{2}$ can depend critically on subtle changes in the stratospheric mean state influenced by the parameterization of orographic gravity waves. More generally, Scaife et al. (2011) show that stratosphere-tropospheric interactions can influence twenty-first-century climate change predictions for the Atlantic storm track, with substantial impacts on the hydrological cycle over Europe.

\section{OPEN QUESTIONS AND NEW FRONTIERS.}

While advances in our understanding of stratospheretroposphere interactions have raised the possibility of improving weather and climate prediction, there remain important questions in how to utilize these gains. From a conceptual and practical standpoint, it is not entirely clear what is necessary to capture a "well represented" stratosphere for the purposes of climate or weather prediction. Adding more model layers and stratospheric processes (such as nonorographic gravity waves, stratospheric chemistry, and microphysics) comes with significant computational expense. Hence, the relevant question is, how much of the stratosphere needs to be represented in a model to capture its influence on the troposphere? From a scientific perspective, a better understanding of the mechanisms coupling the stratosphere to other components of the Earth system is also needed.

Mechanisms. A key coupling between the stratosphere and troposphere is the link between the strength of the stratospheric polar vortex and the position of the troposphere midlatitude jet and storm track, as illustrated on intraseasonal and decadal time scales in Figs. 3 and 4, respectively. Several mechanisms have been proposed, but it has been difficult to isolate the key pathway(s). One view focuses on the balanced response of the troposphere to stratospheric potential vorticity anomalies and wave-driven changes in the meridional circulation (e.g., Hartley et al. 1998; Thompson et al. 2006). A second body of research suggests that the tropospheric response involves changes in synoptic eddies (e.g., Kushner and Polvani 2004; Song and Robinson 2004). Mechanisms based on linear theory highlight the influence of lower-stratospheric conditions on the refraction of synoptic waves (Limpasuvan and Hartmann 2000; Simpson et al. 2009) and the potential for constructive and destructive influence of climatological and forced planetary waves (Fletcher and Kushner 2011). Lower-stratospheric wind and temperature perturbations may also directly affect baroclinic instability (e.g., Rivière 2011) and impact tropospheric wave breaking (Wittman et al. 2004; Chen and Held 2007; Kunz et al. 2009). The range of possible mechanisms suggests a need for greater connection between our theoretical understanding with observations and model simulations.

Missing physical and chemical processes. Uncertainly also lies in stratospheric processes that can only be parameterized at a current model resolution. Alexander et al. (2010) highlight concerns about the treatment of unresolved gravity waves. Most gravity wave parameterizations are highly idealized, in part for a lack of observational constraints, but also to maintain their computational efficiency. Simplification of gravity wave sources limits their potential to evolve in a changing climate. The role of interactive ozone chemistry is also a partially open question. As seen in Fig. 4, CMIP3 models driven with prescribed ozone loss and recovery capture the firstorder effect of ozone on the troposphere, but Waugh et al. (2009b) caution that they may underestimate the response when compared to a fully interactive 
simulation. Last, the transport of water vapor into the stratosphere, which plays a key role in both chemistry and radiation (Solomon et al. 2010), appears sensitive to microphysical processes in the tropical tropopause layer (e.g., Fueglistaler et al. 2009). Gettelmen et al. (2010) find that the representation of tropical tropopause temperatures and water vapor varies considerably in current Chemistry-Climate Models.

Stratospheric climate change. Understanding these unresolved processes may be important for predicting the effects of anthropogenic climate forcing on the stratosphere itself, which is necessary for capturing the impact of the stratosphere on the world below. For example, integrations with Chemistry-Climate Models suggest that the Brewer-Dobson circulation is strengthening and will continue to do so throughout the twenty-first century (e.g., Butchart and Scaife 2001; Butchart et al. 2010). An analysis of stratospheric tracers over the last three decades, however, suggests a weakening of mass transport (Engel et al. 2009), although model trends cannot be ruled out because of substantial uncertainty in the observations (e.g., Garcia et al. 2011). The model trends are consistent with a rise of wave breaking associated with anthropogenic forcing (Calvo and Garcia 2009; Shepherd and McLandress 2011), while Bönisch et al. (2011) argue that the differences in observations and models could be evidence of structural changes in the meridional overturning. If the Brewer-Dobson circulation does increase, leading to greater mass transport from the tropics to the extratropics, then tropical ozone may never recover to preindustrial levels, while extratropical ozone will become larger than ever before (Shepherd 2008; Waugh et al. 2009a). Changing the horizontal gradient of ozone can have important dynamical feedbacks in the stratosphere and troposphere. Changes in the Brewer-Dobson circulation may also be linked to changes in tropical cyclone activity in the North Atlantic. Recent trends in the potential intensity, an indicator of tropical cyclone activity, appear to depend on the temperature trends in the outflow region of the upper troposphere and lower stratosphere, which are sensitive to the stratospheric circulation (Emanuel 2010).

Tropospheric sensitivity. Once stratospheric trends are established, we must also narrow the uncertainty in the tropospheric circulation response to stratospheric perturbations. Son et al. (2010) compare the shift of the austral jet stream in response to ozone loss in several Chemistry-Climate Models. They find a wide range of sensitivity, even when differences in ozone and stratospheric temperatures are taken into account. Models with an equatorward bias in the climatology of the Southern Hemisphere jet stream appear more sensitive to stratospheric perturbations. A similar connection between jet shifts and climatological jet position was found in CMIP3 models (Kidston and Gerber 2010). These biases are associated with enhanced time scales of internal variability, providing a possible explanation through fluctuation-dissipation theory (Gerber et al. 2008; Ring and Plumb 2008).

Stratospheric impacts on Antarctica. A critical question at the frontier of climate prediction is how changes in the Southern Hemisphere atmospheric circulation may affect the Antarctic ice sheets. More rapid melting of the shelf is possible if comparatively warm ocean water is advected to the ice margin. The issue is thus how changes in surface wind stress over the Southern Ocean may affect ocean currents near Antarctica. A small-scale analogue has been studied in detail in the Northern Hemisphere, where changes in ocean circulation driven by natural variability of the jet stream associated with the North Atlantic Oscillation $(\mathrm{NAO})^{2}$ have accelerated the melting of the Jakobshaven Isbræ ice shelf on the western coast of Greenland (Holland et al. 2008). Whether stratospheric-induced wind changes in the Southern Hemisphere could similarly affect Antarctic ice sheets has profound implications for global sea level rise.

The stratosphere and geoengineering. Geoengineering, the deliberate modification of the Earth system to mitigate the effects of global warming, is also at the frontier of climate research. The injection of sulfate aerosols into the stratosphere has been proposed as a possible strategy of "solar radiation management." The assumption is to replicate, enhance, and sustain the global cooling caused by volcanic eruptions to offset warming by greenhouse gasses. A 2009 Royal Society report concluded that this option was potentially among the fastest and least expensive of known geoengineering strategies, but that it was also among the most dangerous in terms of the risk of unintended consequences (Shepherd et al. 2009). While there are growing concerns that microphysical processes, which control the scattering effectiveness and settling rate of aerosols, may limit the cost effectiveness of this strategy (e.g.,

2 The trends in the NAO may have been in part driven by low-frequency variability in the stratosphere (Scaife et al. 2005). 
Niemeier et al. 2011), the strong coupling between the stratosphere with other components of the Earth system alone suggests the need for great caution. The impact of stratospheric aerosols on ozone (Tilmes et al. 2008) and the fact that this mitigation strategy does nothing to stop ocean acidification are other strong causes for concern.

SUMMARY AND OPPORTUNITIES. There is conclusive evidence that the stratosphere plays a significant role in the natural variability and forced response of the Earth system. Better representation of the stratosphere can improve short-range forecasts and provide additional skill on seasonal time scales. Stratospheric ozone loss has played an important role in observed climate trends, in addition to its impact on UV radiation, and will continue to do so well into the twenty-first century. Exploration of the two-way interactions between the stratosphere and troposphere has also raised many questions. New research is required, both at the mechanistic level to piece together the subtle dynamical connections between stratospheric perturbations and tropospheric eddies, and at the global scale to build and assess models that capture all critical parts of the Earth system.

The emerging datasets of stratosphere-resolving models in the CMIP5 and Stratosphere Resolving Historical Forecast Project are a major step forward. They will enable us to better quantify the role of the stratosphere in the observed record and allow for unprecedented exploration of the stratosphere's role in future climate change. The SPARC DynVar activity is coordinating the investigation of these models by organizing research focus groups to assess particular stratospheric processes. Details can be found online (at www.sparcdynvar.org/research-topics-groups -folder/). A key goal for each group is to develop and refine existing metrics to better capture the influence of the stratosphere. Application of these metrics to models with different representations of stratospheric processes and dynamics is an important step in quantifying and understanding the role of the stratosphere in weather and climate.

While much of climate and weather research today justifiably focuses on building more comprehensive and sophisticated prediction systems, the area of stratospheric interactions is also ripe for conceptual work. There is a rich tradition of using simple models to explain and understand the workings of the atmosphere, particularly in the field of stratospheric dynamics. For example, a reduced model of the interaction between the stratospheric polar vortex and tropospheric jet, along the lines of the Holton and Mass (1976) model of a single planetary wave interacting with a stratospheric jet, could provide a major advance in our understanding. There is also room for bold exploration. Just a few years ago, the claim that the halogenated compounds, which used to be contained within everyday aerosol spray cans, could move an entire storm track would have seemed rather preposterous. It is now speculative, but not unreasonable, to ask whether they might help melt an ice sheet. It took many years of dedicated research to link these halogenated compounds to ozone chemistry, ozone changes to stratospheric temperature changes, and stratospheric perturbations to tropospheric circulation anomalies. Will there be another link in the chain? These are exciting times for research on the coupling between the stratosphere and the Earth system.

ACKNOWLEDGMENTS. We thank Dr. Ben Ruston of the Marine Meteorology Division of the Naval Research Laboratory for permission to use the data in Fig. 2, and two anonymous reviewers for their comments on an earlier draft of the manuscript. EPG gratefully acknowledges the support of the National Science Foundation through the Atmospheric and Geospace Sciences program. FS acknowledges the support of the Office of Naval Research through NRL's base 6.1 and 6.2 research programs. JP's contribution is supported by NOAA's Climate Program Office, and MG and EM acknowledge the partial support of the COMBINE project of the European Commission's Seventh Framework Programme.

\section{REFERENCES}

Alexander, M. J., and Coauthors, 2010: Recent developments in gravity-wave effects in climate models and the global distribution of gravity-wave momentum flux from observations and models. Quart. J. Roy. Meteor. Soc., 136, 1103-1124.

Angell, J., 1997: Stratospheric warming due to Agung, El Chichón, and Pinatubo taking into account the quasi-biennial oscillation. J. Geophys. Res., 102 (D8), 9479-9485.

Arblaster, J. M., and G. A. Meehl, 2006: Contributions of external forcings to southern annular mode trends. J. Climate, 19, 2046-2062.

Assmann, R. A., 1902: Über die Existenz eines wärmeren Lufttromes in der Höhe von 10 bis $15 \mathrm{~km}$. Sitzungsber. K. Preuss. Akad. Wiss., 24, 495-504.

Baldwin, M. P., and T. J. Dunkerton, 2001: Stratospheric harbingers of anomalous weather regimes. Science, 294, 581-584. 
—, D. B. Stephenson, D. W. J. Thompson, T. J. Dunkerton, A. J. Charlton, and A. O'Neill, 2003: Stratospheric memory and skill of extended-range weather forecasts. Science, 301, 636-640.

Bell, C. J., L. J. Gray, A. J. Charlton-Perez, M. M. Joshi, and A. A. Scaife, 2009: Stratospheric communication of El Niño teleconnections to European winter. J. Climate, 22, 4083-4096.

Black, R. X., B. A. McDaniel, and W. A. Robinson, 2006: Stratosphere-troposphere coupling during spring onset. J. Climate, 19, 4892-4901.

Boer, G. J., and K. Hamilton, 2008: QBO influence on extratropical predictive skill. Climate Dyn., 31, 987-1000.

Böning, C. W., A. Dispert, M. Visbeck, S. R. Rintoul, and F. U.Schwarzkopf, 2008: The response of the Antarctic Circumpolar Current to recent climate change. Nat. Geosci., 1, 864-869, doi:10.1038/ngeo362.

Bönisch, H., A. Engel, T. Birner, P. Hoor, D. W. Tarasick, and E. A. Ray, 2011: On the structural changes in the Brewer-Dobson circulation after 2000. Atmos. Chem. Phys., 11, 3937-3948.

Boville, B. A., 1984: The influence of the polar night jet on the tropospheric circulation in a GCM. J. Atmos. Sci., 41, 1132-1142.

— , and D. P. Baumhefner, 1990: Simulated forecast error and climate drift resulting from the omission of the upper stratosphere in numerical models. Mon. Wea. Rev., 118, 1517-1530.

Brewer, A. W., 1949: Evidence for a world circulation provided by the measurements of helium and water vapour distribution in the stratosphere. Quart. J. Roy. Meteor. Soc., 75, 351-363.

Brönnimann, S., J. Luterbacker, J. Staehelin, T. M. Svendby, G. Hansen, and T. Svenøe, 2004: Extreme climate of the global troposphere and stratosphere in 1940-42 related to El Niño. Nature, 431, 971-974.

Butchart, N., and A. A. Scaife, 2001: Removal of chlorofluorocarbons by increased mass exchange between the stratosphere and troposphere in a changing climate. Nature, 410, 799-802.

_, and Coauthors, 2010: Chemistry-climate model simulations of twenty-first century stratospheric climate and circulation changes. J. Climate, 23, 5349-5374.

Cagnazzo, C., and E. Manzini, 2009: Impact of the stratosphere on the winter tropospheric teleconnections between ENSO and the North Atlantic and European region. J. Climate, 22, 1223-1238.

Calvo, N., and R. R. Garcia, 2009: Wave forcing of the tropical upwelling in the lower stratosphere under increasing concentrations of greenhouse gases. J. Atmos. Sci., 66, 3184-3196.
—, M. A. Giorgetta, R. Garcia-Herrera, and E. Manzini, 2009: Nonlinearity of the combined warm ENSO and QBO effects on the Northern Hemisphere polar vortex in MAECHAM5 simulations. J. Geophys. Res., 114, D13109, doi:10.1029/ 2008JD011445.

Camp, C. D., and K.-K. Tung, 2007: The influence of the solar cycle and QBO on the late-winter stratospheric polar vortex. J. Atmos. Sci., 64, 1267-1283.

Charlton, A. J., A. O'Neil, W. A. Lahoz, and A. C. Massacand, 2004: Sensitivity of tropospheric forecasts to stratospheric initial conditions. Quart. J. Roy. Meteor. Soc., 130, 1771-1792.

Charney, J. G., and P. G. Drazin, 1961: Propagation of planetary-scale disturbances from the lower into the upper atmosphere. J. Geophys. Res., 66, 83-109.

Chen, G., and I. M. Held, 2007: Phase speed spectra and the recent poleward shift of Southern Hemisphere surface westerlies. Geophys. Res. Lett., 34, L21805, doi:10.1029/2007GL031200.

Christiansen, B., 2005: Downward propagation and statistical forecast of the near-surface weather. J. Geophys. Res., 110, D14104, doi:10.1029/2004JD005431.

Cohen, J., M. Barlow, P. J. Kushner, and K. Saito, 2007: Stratosphere-troposphere coupling and links with Eurasian land surface variability. J. Climate, 20, 5335-5343.

Coughlin, K., and K.-K. Tung, 2001: QBO signal found at the extratropical surface through northern annular modes. Geophys. Res. Lett., 28, 4563-4566.

Crooks, S. A., and L. J. Gray, 2005: Characterization of the 11-year solar signal using a multiple regression analysis of the ERA-40 dataset. J. Climate, 18, 996-1015.

Dall'Amico, M., P. A. Stott, A. A. Scaife, L. J. Gray, K. H. Rosenlof, and A. Yu. Karpechko, 2010: Impact of stratospheric variability on tropospheric climate change. Climate Dyn., 34, 399-417.

Dobson, G. M. B., 1956: Origin and distribution of polyatomic molecules in the atmosphere. Proc. Roy. Soc. London, 236A, 187-193.

Emanuel, K. A., 2010: Stratospheric cooling and tropical cyclones. Preprints, 29th Conf. on Hurricanes and Tropical Meteorology, Seattle, WA, Amer. Meteor. Soc., 4A.4. [Available online at http://ams.confex .com/ams/29Hurricanes/techprogram/paper _168302.htm.]

Engel, A., and Coauthors, 2009: Age of stratospheric air unchanged within uncertainties over the past 30 years. Nat. Geosci., 2, 28-31.

Eyring, V., T. G. Shepherd, and D. W. Waugh, Eds., 2010: Chemistry-climate model validation. SPARC Rep. 5, WCRP-30, WMO/TD-40, 194 pp. [Available at 
www.sparc-climate.org/publications/sparc-reports /sparc-report-no5/.]

Farman, J. C., B. G. Gardiner, and J. D. Shanklin, 1985: Large losses of total ozone in Antarctica reveal seasonal $\mathrm{CLO}_{x} / \mathrm{NO}_{x}$ interaction. Nature, 315, 207-210.

Fels, S. B., J. D. Mahlman, M. D. Schwarzkopf, and R. W. Sinclair, 1980: Stratospheric sensitivity to perturbations in ozone and carbon dioxide: Radiative and dynamical response. J. Atmos. Sci., 37, 2265-2297.

Fletcher, C. G., and P. J. Kushner, 2011: The role of linear interference in the annular mode response to tropical SST forcing. J. Climate, 24, 778-794.

Fogt, R. L., J. Perlwitz, A. J. Monaghan, D. H. Bromwich, J. M. Jones, and G. J. Marshall, 2009: Historical SAM variability. Part II: Twentiethcentury variability and trends from reconstructions, observations, and the IPCC AR4 models. J. Climate, 22, 5346-5365.

Fueglistaler, S., A. E. Dessler, T. J. Dunkerton, I. Folkins, Q. Fu, and P. W. Mote, 2009: Tropical tropopause layer. Rev. Geophys., 47, RG1004, doi:10.1029/2008RG000267.

Garcia, R. R., W. J. Randel, and D. E. Kinnison, 2011: On the determination of age of air trends from atmospheric trace species. J. Atmos. Sci., 68, 139-154.

Garcia-Herrera, R., N. Calvo, R. R. Garcia, and M. A. Giorgetta, 2006: Propagation of ENSO temperature signals into the middle atmosphere: A comparison of two general circulation models and ERA-40 reanalysis data. J. Geophys. Res., 111, D06101, doi:10.1029/2005JD006061.

Gerber, E. P., and L. M. Polvani, 2009 : Stratosphere-troposphere coupling in a relatively simple AGCM: The importance of stratospheric variability. J. Climate, 22, 1920-1933.

— S. Voronin, and L. M. Polvani, 2008: Testing the annular mode autocorrelation time scale in simple atmospheric general circulation models. Mon. Wea. Rev., 136, 1523-1536.

—, C. Orbe, and L. M. Polvani, 2009: Stratospheric influence on the tropospheric circulation revealed by idealized ensemble forecasts. Geophys. Res. Lett., 36, L24801, doi:10.1029/2009GL040913.

Gettelman, A., and Coauthors, 2010: Multimodel assessment of the upper troposphere and lower stratosphere: Tropics and global trends. J. Geophys. Res., 115, D00M08, doi:10.1029/2009JD013638.

Gray, L. J., and Coauthors, 2010: Solar influences on climate. Rev. Geophys., 48, RG4001, doi:10.1029/2009RG000282.

Haigh, J. D., 1996: The impact of solar variability on climate. Science, 272, 981-984.
—, A. R. Winning, R. Toumi, and J. W. Harder, 2010: An influence of solar spectral variations on radiative forcing of climate. Nature, 467, 696-699.

Hartley, D. E., J. T. Villarin, R. X. Black, and C. A. Davis, 1998: A new perspective on the dynamical link between the stratosphere and troposphere. Nature, 391, 471-474.

Hoinka, K. P., 1997: The tropopause: Discovery, definition, and demarcation. Meteor. Z., 6, 281-303.

Holland, D. M., R. H. Thomas, B. deYoung, and M. H. Ribergaard, 2008: Acceleration of Jakobshavn Isbræ triggered by warm subsurface ocean waters. Nat. Geosci., 1, 659-664.

Holton, J. R., and C. Mass, 1976: Stratospheric vacillation cycles. J. Atmos. Sci., 33, 2218-2225.

— , and H.-C. Tan, 1980: The influence of the equatorial quasi-biennial oscillation on the global circulation at $50 \mathrm{mb}$. J. Atmos. Sci., 37, 2200-2208.

Ineson, S., and A. A. Scaife, 2009: The role of the stratosphere in the European climate response to El Niño. Nat. Geosci., 2, 32-36.

Jung, T., and J. Barkmeijer, 2006: Sensitivity of the tropospheric circulation to changes in the strength of the stratospheric polar vortex. Mon. Wea. Rev., 134, 2191-2207.

Kang, S. M., L. M. Polvani, J. C. Fyfe, and M. Sigmond, 2011: Impact of polar ozone depletion on subtropical precipitation. Science, 332, 951-954, doi:10.1126/ science.1202131.

Kidston, J., and E. P. Gerber, 2010: Intermodel variability of the poleward shift of the austral jet stream in the CMIP3 integrations linked to biases in 20th century climatology. Geophys. Res. Lett., 37, L09708, doi:10.1029/2010GL042873.

Kodera, K., and Y. Kuroda, 2002: Dynamical response to the solar cycle. J. Geophys. Res., 107, 4749, doi:10.1029/2002JD002224.

Kolstad, E. W., T. Breiteig, and A. A. Scaife, 2010: The association between stratospheric weak polar vortex events and cold air outbreaks in the Northern Hemisphere. Quart. J. Roy. Meteor. Soc., 136, 886-893.

Kunz, T., K. Fraedrich, and F. Lunkeit, 2009: Synoptic scale wave breaking and its potential to drive NAOlike circulation dipoles: A simplified GCM approach. Quart. J. Roy. Meteor. Soc., 135, 1-19.

Kuroda, Y., 2008: Role of the stratosphere on the predictability of medium-range weather forecast: A case study of winter 2003-2004. Geophys. Res. Lett., 35, L19701, doi:10.1029/2008GL034902.

Kushner, P. J., and L. M. Polvani, 2004: Stratospheretroposphere coupling in a relatively simple AGCM: The role of eddies. J. Climate, 17, 629-639. 
— I. M. Held, and T. L. Delworth, 2001: Southern Hemisphere atmospheric circulation response to global warming. J. Climate, 14, 2238-2249.

Labitzke, K. G., 1972: Temperature changes in the mesosphere and stratosphere connected with circulation changes in winter. J. Atmos. Sci., 29, 756-766.

— , and H. Van Loon, 1999: The Stratosphere: Phenomena, History, and Relevance. Springer-Verlag, $179 \mathrm{pp}$.

Lean, J. L., and D. H. Rind, 2008: How natural and anthropogenic influences alter global and regional surface temperatures: 1889 to 2006. Geophys. Res. Lett., 35, L18701, doi:10.1029/2008GL034864.

Lenton, A., F. Codron, L. Bopp, N. Metzl, P. Cadule, A. Tagliabue, and J. Le Sommer, 2009: Stratospheric ozone depletion reduces ocean carbon uptake and enhances ocean acidification. Geophys. Res. Lett., 36, L12606, doi:10.1029/2009GL038227.

Limpasuvan, V., and D. L. Hartmann, 2000: Wavemaintained annular modes of climate variability. $J$. Climate, 13, 4414-4429.

— - _ D. W. J. Thompson, K. Jeev, and Y. L. Yung, 2005: Stratosphere-troposphere evolution during polar vortex intensification. J. Geophys. Res., 110, D24101, doi:10.1029/2005JD006302.

Lovenduski, N. S., N. Gruber, and S. C. Doney, 2008: Toward a mechanistic understanding of the decadal trends in the Southern Ocean carbon sink. Global Biogeochem. Cycles, 22, GB3016, doi:10.1029/2007gb003139.

Manzini, E., and Coauthors, 2011: Report on the SPARC DynVar Workshop 2 on modelling the dynamics and variability of the stratosphere-troposphere system. SPARC Newsletter, No. 36, SPARC International Project Office, Zurich, Switzerland, 19-22.

Marsh, D. R., and R. R. Garcia, 2007: Attribution of decadal variability in lower-stratospheric tropical ozone. Geophys. Res. Lett., 34, L21807, doi:10.1029/2007GL030935.

Marshall, A. G., and A. A. Scaife, 2009: Impact of the QBO on surface winter climate. J. Geophys. Res., 114, D18110, doi:10.1029/2009JD011737.

— _ _ - and S. Ineson, 2009: Enhanced seasonal prediction of European winter warming following volcanic eruptions. J. Climate, 22, 6168-6180.

Matsuno, T., 1971: A dynamical model of the stratospheric sudden warming. J. Atmos. Sci., 28, 1479-1494.

Matthes, K., Y. Kuroda, K. Kodera, and U. Langematz, 2006: Transfer of the solar signal from the stratosphere to the troposphere: Northern winter. J. Geophys. Res., 111, D06108, doi:10.1029/2005JD006283.

McLandress, C., T. G. Shepherd, J. F. Scinocca, D. A. Plummer, M. Sigmond, A. I. Jonsson, and M. C.
Reader, 2011: Separating the dynamical effects of climate change and ozone depletion. Part II: Southern Hemisphere troposphere. J. Climate, 24, 1850-1868.

McTaggart-Cowan, R., C. Girard, A. Plante, and M. Desgagné, 2011: The utility of upper-boundary nesting in NWP. Mon. Wea. Rev., 139, 2117-2144.

Mukougawa, H., T. Hirooka, and Y. Kuroda, 2009: Influence of stratospheric circulation on the predictability of the tropospheric northern annular mode. Geophys. Res. Lett., 36, L08814, doi:10.1029/2008GL037127.

National Research Council, 2010: Assessment of Intraseasonal to Interannual Climate Prediction and Predictability. National Academies Press, 192 pp.

Newman, P. A., and J. E. Rosenfield, 1997: Stratospheric thermal damping times. Geophys. Res. Lett., 24, 433-436.

Niemeier, U., H. Schmidt, and C. Timmreck, 2011: The dependency of geoengineered sulfate aerosol on the emission strategy. Atmos. Sci. Lett., 12, 189-194.

Pawson, S., and Coauthors, 2000: The GCM-Reality Intercomparison Project for SPARC (GRIPS): Scientific issues and initial results. Bull. Amer. Meteor. Soc., 81, 781-796.

Perlwitz, J., and N. Harnik, 2003: Observational evidence of a stratospheric influence on the troposphere by planetary wave reflection. J. Climate, 16, 3011-3026.

— S. Pawson, R. Fogt, J. E. Nielsen, and W. D. Neff, 2008: Impact of stratospheric ozone hole recovery on Antarctic climate. Geophys. Res. Lett., 35, L08714, doi:10.1029/2008GL033317.

Polvani, L. M., and D. W. Waugh, 2004: Upward wave activity flux as a precursor to extreme stratospheric events and subsequent anomalous surface weather regimes. J. Climate, 17, 3548-3554.

—, — - G. J. P. Correa, and S.-W. Son, 2011: Stratospheric ozone depletion: The main driver of twentieth-century atmospheric circulation changes in the Southern Hemisphere. J. Climate, 24, 795-812.

Ring, M. J., and R. A. Plumb, 2008: The response of a simplified GCM to axisymmetric forcings: Applicability of the fluctuation-dissipation theorem. $J$. Atmos. Sci., 65, 3880-3898.

Rivière, G., 2011: A dynamical interpretation of the poleward shift of the jet streams in global warming scenarios. J. Atmos. Sci., 68, 1253-1272.

Robock, A., and J. Mao, 1992: Winter warming from large volcanic eruptions. Geophys. Res. Lett., 19, 2405-2408.

— and — 1995: The volcanic signal in surface temperature observations. J. Climate, 8, 1086-1103. 
Roff, G., D. W. J. Thompson, and H. Hendon, 2011: Does increasing model stratospheric resolution improve extended-range forecast skill? Geophys. Res. Lett., 38, L05809, doi:10.1029/2010GL046515.

Scaife, A. A., J. R. Knight, G. K. Vallis, and C. K. Folland, 2005: A stratospheric influence on the winter NAO and North Atlantic surface climate. Geophys. Res. Lett., 32, L18715, doi:10.1029/2005GL023226.

_- and Coauthors, 2011: Climate change projections and stratosphere-troposphere interaction. Climate Dyn., doi:10.1007/s00382-011-1080-7.

Scherhag, R., 1952: Die Explosionsartige Stratosphärenerwärmung des Spätwinters 1951/52. Ber. Dtsch. Wetterdienstes U.S. Zone, 6, 51-63.

Schimanke, S., J. Körper, T. Spangehl, and U. Cubasch, 2011: Multi-decadal variability of sudden stratospheric warmings in an AOGCM. Geophys. Res. Lett., 38, L01801, doi:10.1029/2010GL045756.

Shaw, T. A., J. Perlwitz, N. Harnik, P. A. Newman, and S. Pawson, 2011: The impact of stratospheric ozone changes on downward wave coupling in the Southern Hemisphere. J. Climate, 24, 4210-4229.

Shepherd, J., and Coauthors, 2009: Geoengineering the climate: Science, governance and uncertainty. Royal Society Policy Document 10/09, 83 pp.

Shepherd, T. G., 2008: Dynamics, stratospheric ozone, and climate change. Atmos.-Ocean, 46, 371-392.

— - and C. McLandress, 2011: A robust mechanism for strengthening of the Brewer-Dobson circulation in response to climate change: Critical-layer control of subtropical wave breaking. J. Atmos. Sci., 68, 784-797.

Sigmond, M., and J. C. Fyfe, 2010: Has the ozone hole contributed to increased Antarctic sea ice extent? Geophys. Res. Lett., 37, L18502, doi:10.1029/2010GL044301.

— J. F. Scinocca, and P. J. Kushner, 2008: Impact of the stratosphere on tropospheric climate change. Geophys. Res. Lett., 35, L12706, doi:10.1029/2008GL033573.

Simpson, I. R., M. Blackburn, and J. D. Haigh, 2009: The role of eddies in driving the tropospheric response to stratospheric heating perturbations. J. Atmos. Sci., 66, 1347-1365.

Solomon, S., 1999: Stratospheric ozone depletion: A review of concepts and history. Rev. Geophys., 37, 275-316.

—, K. H. Rosenlof, R. W. Portmann, J. S. Daniel, S. M. Davis, T. J. Sanford, and G.-K. Plattner, 2010: Contributions of stratospheric water vapor to decadal changes in the rate of global warming. Science, 327, 1219-1223.

Son, S.-W., and Coauthors, 2008: The impact of stratospheric ozone recovery on the Southern Hemisphere westerly jet. Science, 320, 1486-1489.

— ozone on Southern Hemisphere circulation change:
A multimodel assessment. J. Geophys. Res., 115, D00M07, doi:10.1029/2010JD014271.

Song, Y., and W. A. Robinson, 2004: Dynamical mechanisms for stratospheric influences on the troposphere. J. Atmos. Sci., 61, 1711-1725.

Teisserenc de Bort, L., 1902: Variations de la temperature de l'air libre dans la zone comprise entre $8 \mathrm{~km}$ et 13 km d'altitude. C. R. Acad. Sci., Paris, 138, 42-45.

Thompson, D. W. J., and J. M. Wallace, 1998: The Arctic Oscillation signature in the wintertime geopotential height and temperature fields. Geophys. Res. Lett., 25, 1297-1300.

— and — 2001: Regional climate impacts of the Northern Hemisphere annular mode. Science, 293, 85-89.

— - and S. Solomon, 2002: Interpretation of recent Southern Hemisphere climate change. Science, 296, 895-899.

—, M. P. Baldwin, and J. M. Wallace, 2002: Stratospheric connection to Northern Hemisphere wintertime weather: Implications for prediction. J. Climate, 15, 1421-1428.

— J. J. Furtado, and T. G. Shepherd, 2006: On the tropospheric response to anomalous stratospheric wave drag and radiative heating. J. Atmos. Sci., 63, 2616-2629.

Tilmes, S., R. Müller, and R. Salawitch, 2008: The sensitivity of polar ozone depletion to proposed geoengineering schemes. Science, 320, 1201-1204, doi:10.1126/science.1153966.

Turner, J., and Coauthors, 2009: Nonannular atmospheric circulation change induced by stratospheric ozone depletion and its role in the recent increase of Antarctic sea ice extent. Geophys. Res. Lett., 36, L08502, doi:10.1029/2009GL037524.

Waugh, D. W., L. Oman, S. R. Kawa, R. S. Stolarski, S. Pawson, A. R. Douglass, P. A. Newman, and J. E. Nielsen, 2009a: Impacts of climate change on stratospheric ozone recovery. Geophys. Res. Lett., 36, L03805, doi:10.1029/2008GL036223.

_ _ _ - P. A. Newman, R. S. Stolarski, S. Pawson, J. E. Nielsen, and J. Perlwitz, 2009b: Effect of zonal asymmetries in stratospheric ozone on simulated Southern Hemisphere climate trends. Geophys. Res. Lett., 36, L18701, doi:10.1029/2009GL040419.

Wittman, M. A. H., L. M. Polvani, R. K. Scott, and A. J. Charlton, 2004: Stratospheric influence on baroclinic lifecycles and its connection to the Arctic Oscillation. Geophys. Res. Lett., 31, L16113, doi:10.1029/2004GL020503.

Yin, J. H., 2005: A consistent poleward shift of the storm tracks in simulations of 21st century climate. Geophys. Res. Lett., 32, L18701, doi:10.1029/2005GL023684. 